\title{
Determinants of baseline lung function and bronchodilator response in 4-year-old children
}

\author{
Sandra Dom¹, Joost J. Weyler ${ }^{1}$, Jos H.J. Droste ${ }^{1}$, Margo M. Hagendorens ${ }^{2,3}$, \\ Elke Dierckx², Chris H. Bridts ${ }^{3}$, Wilfried De Backer ${ }^{4}$ and Ellie Oostveen ${ }^{4}$
}

Affiliations: ${ }^{1}$ Dept of Epidemiology and Social Medicine, University of Antwerp, Antwerp, Belgium. ${ }^{2}$ Dept of Paediatrics, Antwerp University Hospital, Antwerp, Belgium. ${ }^{3}$ Dept of Immunology, Allergology and Rheumatology, University of Antwerp and Antwerp University Hospital, Antwerp, Belgium. ${ }^{4}$ Dept of Pulmonary Medicine, Antwerp University Hospital and University of Antwerp, Antwerp, Belgium.

Correspondence: Ellie Oostveen, Dept of Pulmonary Medicine, Antwerp University Hospital, Wilrijkstraat 10, 2650 Antwerp, Belgium. E-mail: ellie.oostveenduza.be

ABSTRACT The prolonged period required for maturation of the respiratory system makes it vulnerable to environmental exposure. This study aimed to investigate the association between early-life factors and lung function in preschool children.

Children aged 4 years, who were included in a prospective birth cohort, underwent lung function testing at baseline $(n=535)$ and after bronchodilation $(n=498)$ by forced oscillations. Information on symptoms and exposures was collected through half-yearly questionnaires. Allergen-specific serum IgE was quantified at 1 and 4 years.

Multiple linear regression analysis showed that the baseline respiratory resistance and reactance area were larger in the children with previous wheeze, those with early-onset sensitisation to inhalant allergens and those who were smaller. Furthermore, children with previous lower respiratory tract infections exhibited higher baseline resistance values. The baseline resistance was the only independent determinant of the bronchodilator-induced change in resistance, whereas current height and baseline reactance area were independently associated with the change in reactance area.

In conclusion, previous lower respiratory tract infections, the timing of previous wheeze, inhalant sensitisation and current height independently influence the baseline lung function of 4-year-old children, whereas baseline lung function is the principal determinant of the bronchodilator response.

@ERSpublications

Height, LRTIs, wheeze and sensitisation to inhalant allergens are determinants of lung function in preschool children http://ow.ly/x6vlH

This article has supplementary material available from erj.ersjournals.com

Received: April 062012 | Accepted after revision: May 022014 | First published online: June 262014

Support statement: This work was supported by the Research Foundation - Flanders (FWO), Belgium (grant 7.0015.00) and the Flemish Government (grant PBO98/26/143).

Conflict of interest: Disclosures can be found alongside the online version of this article at erj.ersjournals.com

Copyright @ERS 2014 


\section{Introduction}

Lung function techniques are important tools for the diagnosis and prognosis of asthma, a complex disease wherein the normal development of the respiratory and immune system is compromised by genetic and environmental factors. Several studies have shown that a reduced lung function at young age is associated with both poorer lung function and a worse asthma outcome later in life [1-3].

There is strong evidence that the majority of asthma originates very early in life [4]. Furthermore, during the first few years of life, the respiratory system undergoes considerable growth and development. Evaluation of lung function in the preschool period is therefore important. Unfortunately, in early childhood, reliable measurements of the lung function can rarely be obtained by standard lung function techniques such as forced expiration. However, a number of techniques for lung function assessment at a preschool age have recently been standardised [5]. The use of these techniques will lead to a better understanding of the development and growth of the human respiratory system, and may provide additional information on the pathophysiological mechanisms involved in asthma.

Various early-life factors have been associated with asthma and lung function in children, including birth and pregnancy characteristics $[6,7]$, the parental atopic status $[6,8]$, and exposure to tobacco smoke [9], allergens [6, 10] and infections [6, 11]. So far, however, few studies have been made of early-life determinants of the baseline lung function and bronchodilator response in preschool children, other than merely anthropometric factors [12-14].

The present study was designed to investigate which early-life factors are associated with baseline lung function and bronchodilator response in a large population of 4-year-old children included in a birth cohort.

\section{Methods}

\section{Study design and population}

This study comprised part of the investigations of the PIPO (Prospective Cohort on the Influence of Perinatal Factors on the Occurrence of Asthma and Allergies), a prospective birth cohort in Antwerp, Belgium. Between June 1997 and December 2001, pregnant females were invited to participate by completing a screening questionnaire. Data on demography, health status and the environmental exposure of the children were collected through two home visits (at 5 months of pregnancy and 3 months after birth) and 6-month questionnaires (modified from the questionnaires of the ISAAC (International Study on Asthma and Allergies in Childhood) [15]) from 1 year of age. At 1 and 4 years of age, the children were invited to visit the Antwerp University Hospital for a medical examination and blood sampling. Additionally, at the age of 4 years, the baseline lung function and the bronchodilator response were assessed through use of the forced oscillation technique (FOT). The children who regularly used bronchodilators were asked to abstain from their use on the examination day, whereas the use of inhaled corticosteroids was not interrupted. In the event of illness, the date of the visit was altered. All parts of the project were approved by the Medical Ethics Committee of the University of Antwerp and written informed consent was obtained from the children's parents before each assessment.

\section{Lung function measurements}

The respiratory impedance $(Z \mathrm{rs})$ was measured in the frequency range $4-32 \mathrm{~Hz}$ by using a custom-made setup that met the American Thoracic Society/European Respiratory Society requirements [5, 16]. Measurements were performed in accordance with recent international guidelines [5]. Recordings lasted for $16 \mathrm{~s}$ and at least three to five acceptable $Z$ rs data sets were obtained, which were used to calculate the mean values for the respiratory resistance (Rrs) and reactance (Xrs). After the baseline $Z$ rs measurement, $200 \mu \mathrm{g}$ salbutamol was administered through a spacer (OptiChamber; Respironics New Jersey Inc., Parsipanny, NJ, USA) and the $Z$ rs measurement was repeated 15 min thereafter. A more detailed description of the lung function measurements and the data analysis has been published previously [17]. To characterise the baseline lung function and the bronchodilator response, the respiratory resistance at $6 \mathrm{~Hz}\left(\operatorname{Rrs}_{6}\right)$ was analysed and the area under the reactance curve (AX), i.e. the integrated area of all Xrs data points below zero from $4 \mathrm{~Hz}$ up to the resonant frequency, was determined. The changes in $\mathrm{Rrs}_{6}$ and $\mathrm{AX}$ after bronchodilation $\left(\Delta \operatorname{Rrs}_{6}\right.$ and $\Delta \mathrm{AX}$, respectively) were expressed relative to the corresponding baseline value $\left(\Delta=\right.$ (post-pre)/pre). $\Delta \operatorname{Rrs}_{6}$ was also expressed as $\mathrm{z}$-score change $\left(\Delta \operatorname{Rrs}_{6}(\mathrm{Z}\right.$-score $\left.)\right)$ using a previously published prediction equation incorporating a coefficient for height and weight [18]. The analysis of baseline $\operatorname{Rrs}$ at $4 \mathrm{~Hz}$ and $8 \mathrm{~Hz}$, and the respiratory admittance at $6 \mathrm{~Hz}$ can be found in the online supplementary material. 
Potential determinants of lung function

Potential determinants of the lung function and bronchodilator response were selected from the literature $[6-14,19,20]$. The following potential determinants were considered: gestational age; the child's birth weight and sex; prenatal exposure to cats or dogs; maternal smoking during pregnancy; parental doctordiagnosed asthma; eczema or hay fever in the parents; contact with cats or dogs; environmental tobacco smoke (ETS); and lower respiratory tract infections (LRTIs), defined as a serious lung or airway infection. LRTIs, and exposure to cats, dogs or ETS were divided into three categories according to the timing of the first occurrence: 1) never; 2) for the first time in the first year of life; and 3) after the first year of life. The history of wheeze was categorised into the following phenotypes: never, early/transient, late-onset and persistent wheeze $[17,21]$. Furthermore, the number of LRTIs and wheeze episodes were divided into three categories: 1) none; 2) one; and 3) more than one.

\section{Assessment of sensitisation}

At 1 and 4 years of age, a blood sample was taken to quantify allergen-specific IgE (details have been published previously [17]). Inhalant sensitisation (against Dermatophagoides pteronyssimus, cat dander, dog dander, birch pollen (Betula verrucosa) and/or timothy grass pollen (Phleum pratense) and food sensitisation (against hen's egg and/or cow's milk) were both divided into three categories: never sensitised, sensitised for the first time at the age of 1 year (i.e. early sensitisation) and sensitised for the first time at the age of 4 years (i.e. late sensitisation). The number of allergens to which the child was sensitised was also divided into three categories: 1) no sensitisation, 2) sensitisation to one allergen and 3) sensitisation to more than one allergen.

\section{Statistical analyses}

After the testing for normality with the Kolmogorov-Smirnov test, $\operatorname{Rrs}_{6}, \mathrm{AX}, \Delta \operatorname{Rrs}_{6}(\mathrm{z}$-score) and $\Delta \mathrm{AX}$ were transformed $\left(\log _{10} R \operatorname{Rr}_{6}, \log _{10} \mathrm{AX}, \log _{10}\left(-\Delta \operatorname{Rrs}_{6}(\mathrm{z}\right.\right.$-score $\left.)+2\right)$ and $\sqrt{ }(\Delta \mathrm{AX}+100)$, respectively) to allow for the normal distribution assumption. The bronchodilator response of $\operatorname{Rrs}_{6}$ expressed relative to the baseline value did not need transformation. Crude associations between the independent variables and the outcome variables were tested by the independent-sample t-test, one-way ANOVA with the least-significant difference post hoc test or simple linear regression analyses. A p-value $<0.10$ was used as the criterion for selecting the variables for multiple linear regression analysis. Model reduction on the initial multiple linear regression model was performed by stepwise backward elimination based on the criterion $\mathrm{p}<0.05$. Plots of the residuals were inspected visually to verify model assumptions. All statistical analyses were performed with SPSS for Windows, version 18 (SPSS Inc., Chicago, IL, USA).

\section{Results}

Population characteristics

Of the 1128 children included in the cohort at birth, 577 (51.1\%) attended the 4-year follow-up. For 567 of these children, permission was given for lung function testing. In 543 (95.8\%) of these 567 children, FOT was successfully performed. Eight children were excluded from the study because of the use of medication $(n=2)$ or unreliable data $(n=6)$. Baseline $Z$ rs data on 535 children and post-bronchodilator $Z$ rs data on 498 children were available for the present study. The characteristics of the study population are presented in table 1 (see the online supplement for a more detailed description).

\section{Determinants of the baseline lung function}

Table 2 relates to the crude associations between the potential determinants and the baseline $\operatorname{Rrs}_{6}$ and AX data. The univariate analyses revealed that current height, current weight and birth weight were significantly negatively associated with the baseline values of $\operatorname{Rrs}_{6}$ and AX. Furthermore, a lower gestational age at delivery was significantly associated with larger baseline values of AX. The occurrence of LRTIs, wheeze and the sensitisation to inhalant allergens were all significantly associated with the baseline lung function, both when expressed in terms of timing of the event in early life as well as the frequency of the event. None of the prenatal exposures was associated with the baseline values of $\operatorname{Rrs}_{6}$ and AX.

Figure 1 presents the back-transformed baseline values of $\operatorname{Rrs}_{6}$ and $\mathrm{AX}$ in the subgroups of children according to the timing of LTRIs. Only the difference between the baseline lung function values of the children without LRTIs and those with a LRTI after the first year of life was statistically significant. The back-transformed baseline values of $\mathrm{Rrs}_{6}$ and $\mathrm{AX}$ in the subgroups of children according to the timing of wheeze is presented in figure 2. Baseline lung function was poorer in children with early/transient, lateonset and persistent wheeze compared with those who never wheezed. Furthermore, the children with lateonset or persistent wheeze had larger values of $\operatorname{Rrs}_{6}$ than those with early/transient wheeze. Figure 3 demonstrates that the back-transformed baseline values of $\operatorname{Rrs}_{6}$ and AX measured for the group of children 


\section{TABLE 1 Characteristics of the group of children $(n=535)$ studied at 4 years of age}

\begin{tabular}{|c|c|}
\hline \multicolumn{2}{|l|}{ Anthropometrics } \\
\hline Males & 50.5 \\
\hline Age years & $4.3 \pm 0.2$ \\
\hline Current height $\mathrm{cm}$ & $106.2 \pm 4.2$ \\
\hline Current weight kg & $17.6 \pm 2.2$ \\
\hline Current $\mathrm{BMI} \mathrm{kg} \cdot \mathrm{m}^{-2}$ & $15.6 \pm 1.3$ \\
\hline \multicolumn{2}{|l|}{ Lung function parameters } \\
\hline \multicolumn{2}{|l|}{$\operatorname{Rrs}_{6}$} \\
\hline Baseline $\mathrm{hPa} \cdot \mathrm{s} \cdot \mathrm{L}^{-1}$ & $10.3 \pm 2.5$ \\
\hline Absolute change $\mathrm{hPa} \cdot \mathrm{s} \cdot \mathrm{L}^{-1}$ & $-2.5 \pm 1.8$ \\
\hline Relative change $\%$ baseline & $-22.6 \pm 13.0$ \\
\hline \multicolumn{2}{|l|}{$A X$} \\
\hline Baseline $\mathrm{hPa} \cdot \mathrm{L}^{-1}$ & $23.9 \pm 19$ \\
\hline Absolute change $\mathrm{hPa} \cdot \mathrm{L}^{-1}$ & $-13.9 \pm 16.5$ \\
\hline Relative change $\%$ baseline & $-48.5 \pm 25.8$ \\
\hline \multicolumn{2}{|l|}{ Birth characteristics } \\
\hline Gestational age weeks & $39.2 \pm 1.6$ \\
\hline Birth weight kg & $3.4 \pm 0.5$ \\
\hline \multicolumn{2}{|l|}{ Family history } \\
\hline \multicolumn{2}{|l|}{ Parental atopy } \\
\hline No & 31.6 \\
\hline Only mother & 21.5 \\
\hline Only father & 27.9 \\
\hline Both parents & 18.9 \\
\hline \multicolumn{2}{|l|}{ Parental allergies } \\
\hline No & 42.5 \\
\hline Only mother & 29.9 \\
\hline Only father & 19.0 \\
\hline Both parents & 8.6 \\
\hline \multicolumn{2}{|l|}{ Parental asthma } \\
\hline No & 86.8 \\
\hline Mother & 7.5 \\
\hline Father & 5.4 \\
\hline Both parents & 0.4 \\
\hline
\end{tabular}

\section{Prenatal exposures}

Prenatal exposure to cat or dog 38.7

Maternal smoking

Postnatal exposures

Postnatal cat or dog

Never

First in first year

First after first year

Postnatal ETS

Never

First in first year

First after first year

LRTI

Never

First in first year

First after first year

Number of LRTIs

0

1

$>1$

Wheeze

Timing of wheeze

Never

Early/transient

Late onset $\quad 2.1$

Persistent 16.3

Number of wheeze episodes

$\begin{array}{ll}0 & 45.7\end{array}$

1218.1

$>1$

Atopic sensitisation

Inhalant atopy

Never $\quad 79.2$

First at 1 year $\quad 5.2$

First at 4 years $\quad 15.6$

Food atopy

Never $\quad 80.0$

First at 1 year $\quad 14.0$

First at 4 years $\quad 6.0$

Number of inhalant allergens $\quad 79.4$

0 r

$>1 \quad 8.3$

Number of food allergens 79.8

$\begin{array}{ll}0 & 79.8 \\ 1 & 14.4\end{array}$

$\begin{array}{ll}>1 & 5.7\end{array}$

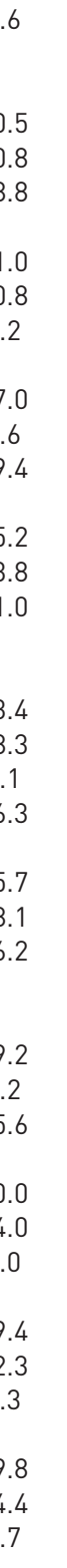

Data are presented as $\%$ or mean + SD. $n=535$. BMI: body mass index; Rrs 6 : respiratory resistance at $6 \mathrm{~Hz}$; $A X$ : area under the reactance curve; ETS: environmental tobacco smoke; LRTI: lower respiratory tract infection.

already sensitised to inhalant allergens at 1 year of age were larger than those for the groups of children who were not sensitised to inhalant allergens, or those sensitised between 1 and 4 years of age. The differences in AX between the separate groups of the timing of LRTIs, wheeze and sensitisation to inhalant allergens were considerably larger than the differences in $\operatorname{Rrs}_{6}$.

The results of the multiple linear regression models with $\log _{10} \operatorname{Rrs}_{6}$ and $\log _{10} \mathrm{AX}$ as outcome variables are presented in table 3. The final models showed that height, LRTIs after the first year of life, the timing of wheeze and early-onset sensitisation against inhalant allergens were independently associated with both baseline $\operatorname{Rrs}_{6}$ and baseline AX. These models explained $16.7 \%$ and $14.6 \%$ of the variation in the baseline values of $\operatorname{Rrs}_{6}$ and AX, respectively. 
TABLE 2 Crude associations between potential determinants and the baseline lung function

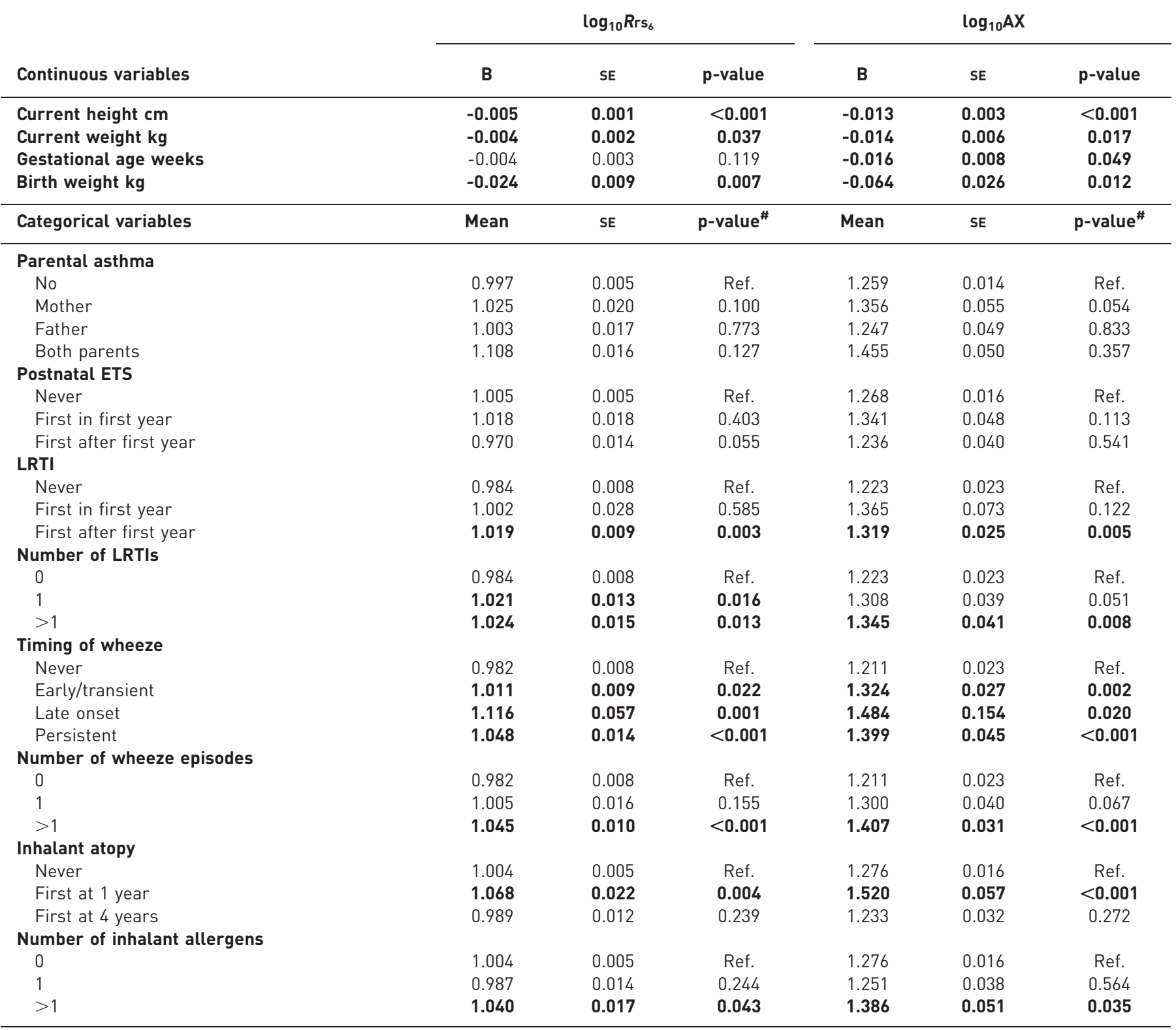

Numbers in bold indicate $\mathrm{p}<0.05$. Rrs 6 : respiratory resistance at $6 \mathrm{~Hz}$; $A X$ : area under the reactance curve; $B$ : unstandardised regression coefficient; ETS: environmental tobacco smoke; LRTI: lower respiratory tract infection. ${ }^{\text {: }}$ : least-significant difference post hoc test.

\section{Determinants of the bronchodilator response}

Univariate analysis revealed that the children with a lower gestational age at birth and those with a lower birth weight exhibited a larger $\Delta \operatorname{Rrs}_{6}$ and $\Delta R \mathrm{rs}_{6}(\mathrm{z}$-score) (table 4). The children who were taller and who weighed more exhibited larger relative changes in $\Delta \mathrm{AX}$ values. Furthermore, the univariate analysis indicated that the bronchodilator response was larger in the children who suffered LRTIs after the first year of life, in those who wheezed and in those with early-onset sensitisation to inhalant allergens. In addition, the number of LRTIs, the number of wheeze episodes and the number of food allergens to which the child was sensitised were positively associated with a larger bronchodilator response.

The results of the multiple linear regression models of $\Delta \operatorname{Rrs}_{6}$ and $\Delta \mathrm{AX}$ are presented in table 5 . Baseline $\operatorname{Rrs}_{6}$ and $\operatorname{Rrs}_{6}(\mathrm{z}$-score $)$ were the only significant independent determinants of $\Delta R \operatorname{Rs}_{6}$ and $\Delta R \operatorname{Rs}_{6}(\mathrm{z}$-score $)$, respectively. Both current height and baseline AX were independently positively associated with $\triangle \mathrm{AX}$. The 

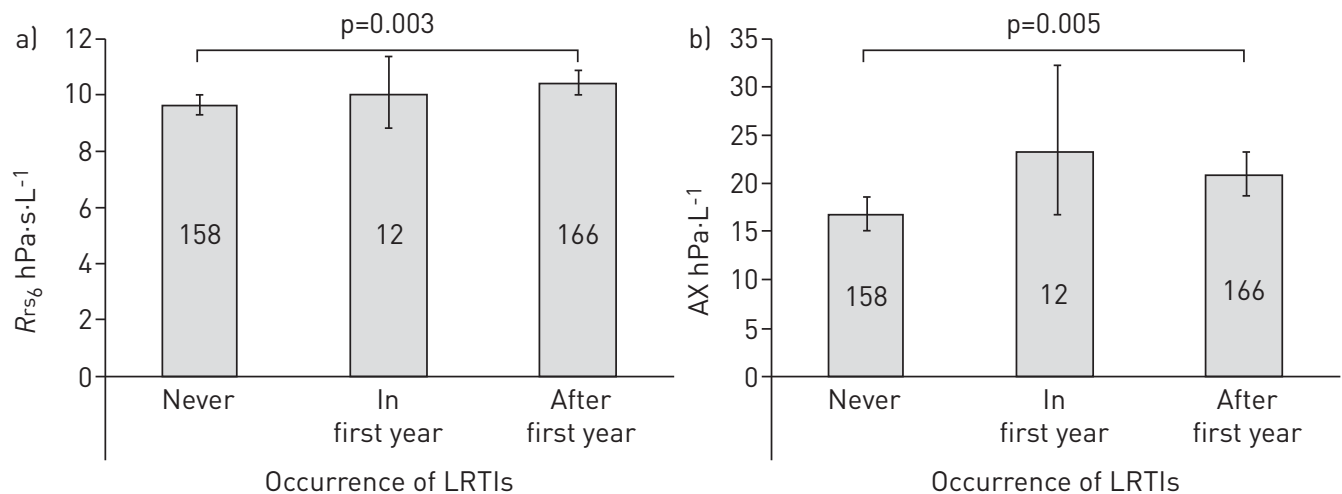

FIGURE 1 Baseline a) respiratory resistance at $6 \mathrm{~Hz}\left(\operatorname{Rrs}_{6}\right)$ and b) area under the reactance curve $(\mathrm{AX})$ in separate groups of 4-year-old children, based on the occurrence and timing of lower respiratory tract infections (LRTIs). Data are presented as back-transformed geometric means with $95 \%$ confidence intervals (error bars). The numbers of children in the separate groups are indicated.

models in which only the baseline lung function values were used as predictors explained $20.8 \%, 45.3 \%$ and $27.4 \%$ of the variation in $\Delta R \mathrm{Rs}_{6}, \Delta R \mathrm{Rs}_{6}(\mathrm{z}$-score $)$ and $\Delta \mathrm{AX}$, respectively.

\section{Discussion}

To the best of our knowledge, this is the first report concerning the influence of multiple early-life factors on baseline lung function and bronchodilator responsiveness in a large population of 4-year-old children included in a birth cohort. Current height, previous LRTIs, the timing of wheeze and early-onset sensitisation to inhalant allergens were found to be independent determinants of the baseline values of $\operatorname{Rrs}_{6}$ and AX in these 4-year-old children. Baseline $\operatorname{Rrs}_{6}$ was the only independent determinant of bronchodilatorinduced $\Delta \operatorname{Rrs}_{6}$, whereas baseline $\mathrm{AX}$ and current height were independently associated with $\Delta \mathrm{AX}$. None of the prenatal exposures considered was associated with baseline lung function or bronchodilator-induced change in lung function. It is important to realise that although our analyses revealed significant associations between some early-life factors and lung function in preschool children, it is impossible to determine whether these relationships are causal.

The present study has several methodological strengths. Firstly, the data were collected prospectively at 6month intervals, which minimised recall bias. Secondly, as the mothers were invited to participate in the study during their pregnancy, the prenatal environment of the child could also be taken into account. However, there was a considerable drop-out rate in the study: only 577 of the initial 1128 children entered the examination at 4 years of age. We believe that this drop-out did not greatly influence the studied associations as it was not selective for the outcome. Children with allergic parents are overrepresented in our study compared with the general Belgian population ( $58 \%$ of the children had one or more allergic parent (table 1), whereas a recently conducted national survey reported a prevalence of $13 \%$ of allergic

a)

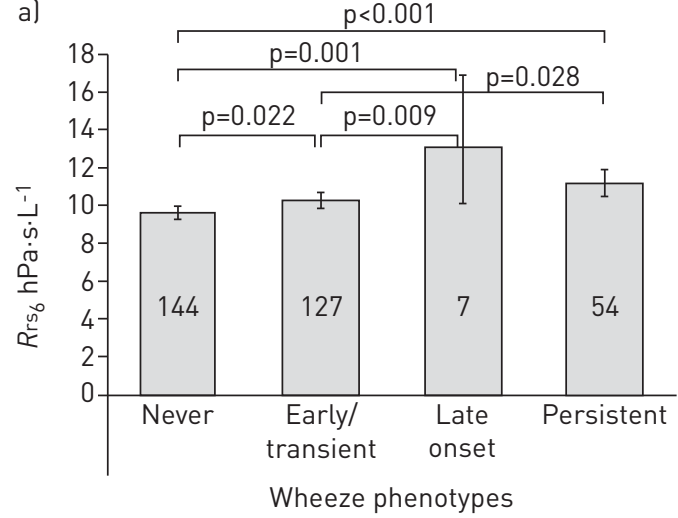

b)

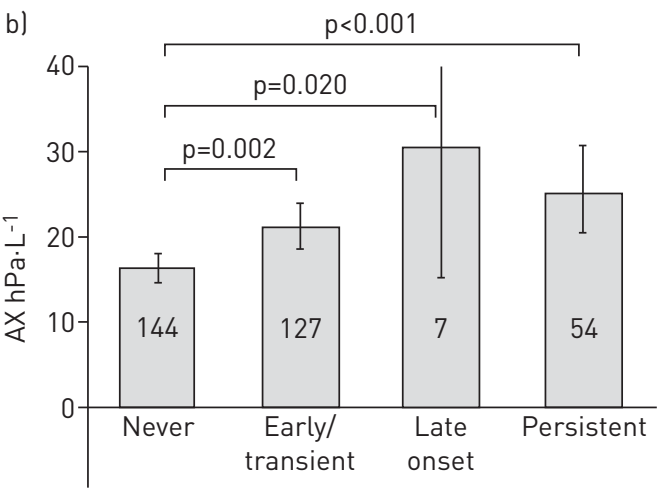

FIGURE 2 Baseline a) respiratory resistance at $6 \mathrm{~Hz}\left(\mathrm{Rrs}_{6}\right)$ and b) area under the reactance curve (AX) in separate groups of 4-year-old children, based on the timing of the occurrence of wheeze. Data are presented as back-transformed geometric means with 95\% confidence intervals (error bars). b) The error bar for late-onset wheeze is truncated. The numbers of children in the separate groups are indicated. 

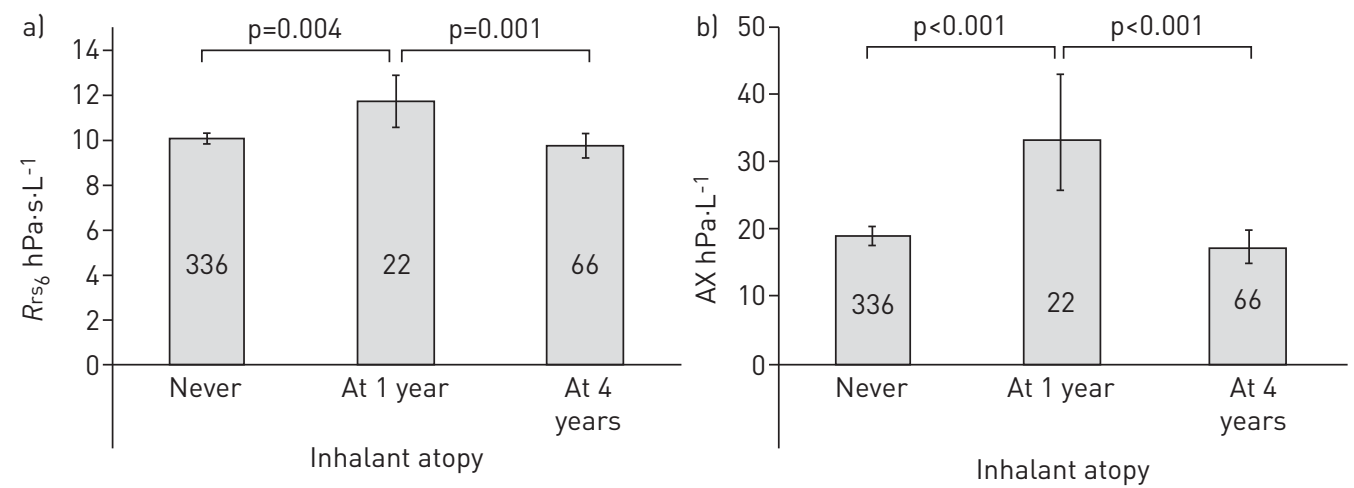

FIGURE 3 Baseline a) respiratory resistance at $6 \mathrm{~Hz}\left(\mathrm{Rrs}_{6}\right)$ and b) area under the reactance curve (AX) in separate groups of 4-year-old children, based on the timing of the sensitisation to inhalant allergens. Data are presented as backtransformed geometric means with $95 \%$ confidence intervals (error bars). The numbers of children in the separate groups are indicated.

diseases in Belgian adults). This selective participation favoured a more balanced distribution of the children in this study population in terms of environmental exposure and allergic sensitisation.

We have presented $\operatorname{Rrs}_{6}$ data but similar results were obtained when $\operatorname{Rrs}$ at 4 or $8 \mathrm{~Hz}$, or the admittance at $6 \mathrm{~Hz}$ was analysed (online supplementary material). AX was chosen as the second outcome because a previous study had revealed that AX is more sensitive than individual values of $X \mathrm{rs}$ at low frequency for discriminating between different wheezing phenotypes in 4-year-old children [17]. Another benefit of AX relative to individual $\mathrm{Xrs}$ data is that AX is less influenced by measurement noise [22]. In the current study, the bronchodilator response was expressed as the relative change compared with the baseline value, as suggested by THAMRIN et al. [14]. Expression of the response as the absolute change or as the change in terms of the z-score, as recently suggested by CALOGERO et al. [12], yielded similar results.

Several previous studies using the FOT in preschool children have demonstrated that current standing height is the main anthropometric determinant of the baseline lung function [12-14, 23]. These previous studies were all cross-sectional studies of healthy children with a broader age and thus height range than those of the children participating in our study. Despite the narrow range in height in our population of 4year-old children, we still observed that current height is an independent determinant of the baseline values of $\operatorname{Rrs}_{6}$ and AX.

\section{TABLE 3 Multiple linear regression models for the determinants of the baseline lung function}

\begin{tabular}{|c|c|c|c|c|c|c|}
\hline Determinants & \multicolumn{3}{|c|}{$\log _{10} R \operatorname{Rs}_{6} \#$} & \multicolumn{3}{|c|}{$\log _{10} A X^{\oplus}$} \\
\hline \multicolumn{7}{|l|}{ LRTI } \\
\hline Never & Ref. & & & & & \\
\hline First in first year & -0.016 & 0.035 & 0.645 & & & \\
\hline Never & Ref. & & & Ref. & & \\
\hline Early/transient & 0.041 & 0.015 & 0.007 & 0.137 & 0.038 & $<0.001$ \\
\hline Late onset & 0.090 & 0.052 & 0.084 & 0.232 & 0.134 & 0.085 \\
\hline Persistent & 0.055 & 0.020 & 0.007 & 0.190 & 0.051 & $<0.001$ \\
\hline \multicolumn{7}{|l|}{ Inhalant sensitisation } \\
\hline Never & Ref. & & & Ref. & & \\
\hline
\end{tabular}

Numbers in bold indicate $\mathrm{p}<0.05$. Rrs 6 : respiratory resistance at $6 \mathrm{~Hz}$; $A X$ : area under the reactance curve; $\mathrm{B}$ : unstandardised regression coefficient; LRTI: lower respiratory tract infection. ${ }^{\#}$ : final model $\left(R^{2}=0.167\right) ;{ }^{9}$ : final model $\left(R^{2}=0.146\right)$. 
TABLE 4 Crude associations between potential determinants and the bronchodilator-induced change in lung function

\begin{tabular}{|c|c|c|c|c|c|c|c|c|c|}
\hline Continuous variables & \multicolumn{3}{|c|}{$\Delta \operatorname{Rrs}_{6} \%$ baseline } & \multicolumn{3}{|c|}{$\log _{10}\left(-\Delta R r s_{6}(z-\right.$ score $\left.)+2\right)$} & \multicolumn{3}{|c|}{$\sqrt{ }(\Delta A X+100) \%$ baseline } \\
\hline Current weight kg & -0.155 & 0.260 & 0.552 & 0.001 & 0.002 & 0.872 & -0.093 & 0.034 & 0.007 \\
\hline Gestational age weeks & 0.793 & 0.364 & 0.030 & -0.008 & 0.003 & 0.024 & 0.084 & 0.048 & 0.083 \\
\hline Birth weight kg & 2.853 & 1.134 & 0.012 & -0.028 & 0.011 & 0.008 & 0.225 & 0.151 & 0.137 \\
\hline \multicolumn{10}{|l|}{ Postnatal ETS } \\
\hline Never & -22.3 & 0.7 & Ref. & 0.505 & 0.007 & Ref. & 6.94 & 0.09 & Ref. \\
\hline First in first year & -26.4 & 2.4 & 0.056 & 0.544 & 0.023 & 0.054 & 6.61 & 0.33 & 0.240 \\
\hline First after first year & -23.6 & 2.2 & 0.596 & 0.500 & 0.020 & 0.825 & 6.74 & 0.25 & 0.514 \\
\hline \multicolumn{10}{|l|}{ LRTI } \\
\hline Never & -20.8 & 1.1 & Ref. & 0.487 & 0.095 & Ref. & 7.26 & 0.14 & Ref. \\
\hline 1 & -24.1 & 1.7 & 0.101 & 0.521 & 0.016 & 0.074 & 6.47 & 0.20 & 0.002 \\
\hline$>1$ & -24.9 & 1.8 & 0.047 & 0.535 & 0.019 & 0.014 & 6.73 & 0.23 & 0.045 \\
\hline \multicolumn{10}{|l|}{ Timing of wheeze } \\
\hline Never & -20.9 & 1.1 & Ref. & 0.487 & 0.097 & Ref. & 7.22 & 0.14 & Ref. \\
\hline Early/transient & -23.0 & 1.2 & 0.207 & 0.512 & 0.011 & 0.113 & 6.79 & 0.15 & 0.047 \\
\hline Late onset & -26.6 & 6.1 & 0.267 & 0.589 & 0.0 .73 & 0.034 & 5.74 & 0.63 & 0.027 \\
\hline Persistent & -25.4 & 2.0 & 0.038 & 0.543 & 0.0 .20 & 0.006 & 6.49 & 0.27 & 0.009 \\
\hline \multicolumn{10}{|c|}{ Number of wheeze episodes } \\
\hline 0 & -20.9 & 1.1 & Ref. & 0.487 & 0.097 & Ref. & 7.22 & 0.14 & Ref. \\
\hline 1 & -23.0 & 1.7 & 0.335 & 0.512 & 0.017 & 0.218 & 6.92 & 0.22 & 0.279 \\
\hline$>1$ & -25.1 & 1.3 & 0.015 & 0.539 & 0.013 & 0.001 & 6.45 & 0.18 & 0.001 \\
\hline \multicolumn{10}{|l|}{ Inhalant atopy } \\
\hline Never & -21.9 & 0.7 & Ref. & 0.502 & 0.007 & Ref. & 7.00 & 0.10 & Ref. \\
\hline First at 1 year & -24.2 & 1.8 & 0.203 & 0.521 & 0.018 & 0.245 & 7.05 & 0.27 & 0.799 \\
\hline First at 4 years & -26.0 & 2.8 & 0.117 & 0.542 & 0.027 & 0.097 & 6.53 & 0.38 & 0.214 \\
\hline \multicolumn{10}{|l|}{ Number of food allergens } \\
\hline 0 & -21.9 & 0.7 & Ref. & 0.501 & 0.006 & Ref. & 6.99 & 0.09 & Ref. \\
\hline 1 & -22.3 & 1.8 & 0.825 & 0.502 & 0.016 & 0.926 & 6.95 & 0.20 & 0.891 \\
\hline$>1$ & -30.3 & 2.4 & 0.002 & 0.571 & 0.022 & 0.005 & 6.84 & 0.55 & 0.686 \\
\hline
\end{tabular}

Numbers in bold indicate $\mathrm{p}<0.05 . \Delta$ : change (expressed as relative change compared to baseline and as $\mathrm{z}$-score); Rrs 6 : respiratory resistance at $6 \mathrm{~Hz}$; AX: area under the reactance curve; B: unstandardised regression coefficient; ETS: environmental tobacco smoke; LRTI: lower respiratory tract infection. \# : least-significant difference post hoc test.

In the previous studies that investigated potential determinants of the lung function in preschool children as assessed with the FOT, only height proved to be a significant predictor of the lung function and, after height was taken into account, neither the presence of atopy in the first-degree relatives or in the child nor ETS significantly affected the baseline lung function $[11-13,24]$. In contrast, our results indicate that besides current height, LRTIs after the first year of life, the timing of wheeze and early sensitisation to inhalant allergens were independent determinants of baseline $\operatorname{Rrs}_{6}$ and $\mathrm{AX}$ in these 4-year-old children. A possible reason why these associations were not found in previous FOT studies is that most of these aimed to obtain normal values of $Z$ rs in smaller populations of healthy children, whereas we enrolled a relatively large sample 
TABLE 5 Multiple linear regression models for the determinants of the bronchodilator-induced change in lung function

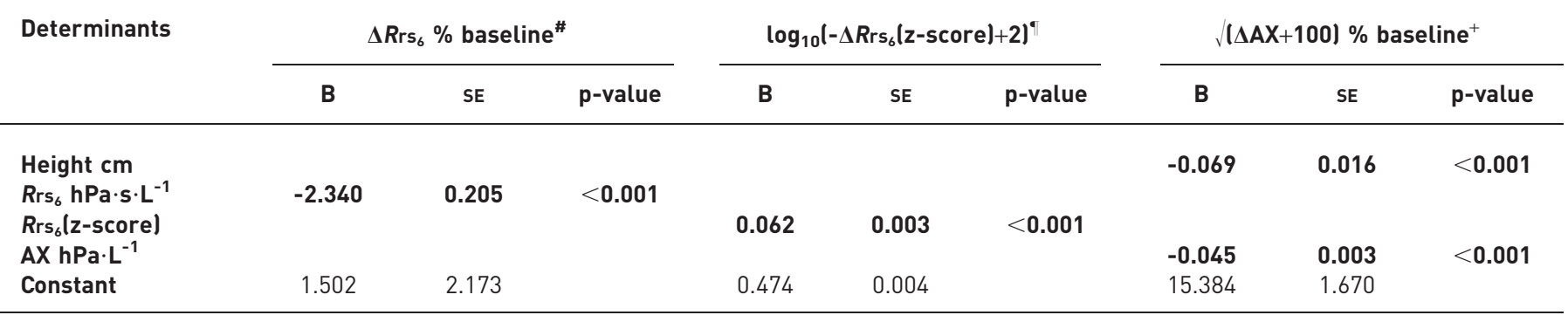

Numbers in bold indicate $\mathrm{p}<0.05 . \Delta$ : change (expressed as relative change compared to baseline and as $\mathrm{z}$-score); Rrs 6 : respiratory resistance at $6 \mathrm{~Hz}$; AX: area under the reactance curve; $B$ : unstandardised regression coefficient. ${ }^{\#}$ : final model $\left(R^{2}=0.208\right) ;{ }^{\circ}$ : final model $\left(R^{2}=0.453\right) ;{ }^{+}$: final model $\left(R^{2}=0.274\right)$

of the general population. Furthermore, our data were collected as part of a longitudinal birth cohort study, whereas the normative studies were based on cross-sectional data.

Whereas both the timing and the amount of LRTIs and wheeze, and the timing of the sensitisation and number of inhalant allergens were significantly associated with baseline lung function in our univariate analysis (table 2), only the timing of the exposures/sensitisation was retained in the final model (table 3 ). Early-onset sensitisation to inhalant allergens (i.e. in the first year of life), an LRTI for the first time after the first year of life and the timing of wheeze (children with late-onset and persistent wheeze having the poorest lung function) significantly worsened the baseline lung function of the 4-year-old children. Although the baseline lung functions of the children who had suffered from an LRTI in the first year of life were also worse than those in the nonexposed children (fig. 1), these differences did not reach statistical significance, most probably due to the low prevalence of LRTIs in the first year of life ( $n=12$ children).

To the best of our knowledge, there has been only one previous large prospective birth cohort study (the NAC Manchester Asthma and Allergy Study) that has reported on early-life determinants of the baseline specific airway resistance (sRaw) in preschool children. On behalf of the study group, LowE et al. [8] reported that symptom-free 3-year-old children with atopic parents and those with a personal history of atopy exhibited an impaired lung function. In another study, the same research group found that parental asthma was an independent predictor of the baseline sRaw of 3-year-old children, as was a combination of sensitisation and exposure to a sensitising allergen, which resulted in a significant deficit in the lung function of the children. However, they did not find an independent effect of atopic sensitisation or exposure to a sensitising allergen alone [10].

Other birth cohort studies have demonstrated that early sensitisation to aeroallergens (at $<3$ years of age) is associated with a loss of lung function at school age, whereas late sensitisation has a less pronounced effect [24]. Our study confirms these observations, and adds that this effect of early sensitisation takes place at $\leqslant 1$ year of age and that the lung function loss is already present at the preschool age. Additionally, previous studies have reported that allergic sensitisation in the first years of life predisposes young children to viral wheezing illnesses [25], which in turn predict a diminished lung function at school age [26]. Other investigators have suggested a possible synergistic effect of allergen-induced and virus-induced inflammation of the airways during infancy that contributes to the pathogenesis of paediatric asthma [27, 28]. Suffering from multiple episodes of LRTIs at early age has been associated with the subsequent development of wheezing [29] and a loss of lung function at the school age [30]. Finally, the question in all these birth cohort studies, including ours, is whether paediatric lung function is already reduced prior to the infantile atopic sensitisation and respiratory symptoms [11]. Evidence that premorbid, diminished lung function is associated with subsequent development of LRTI and wheeze in young children was demonstrated in the hallmark Tucson cohort study [21].

The magnitude of the relative change in $\mathrm{Rrs}_{6}$ after bronchodilation in preschool children as measured in this study $\left(-23 \%\right.$ for $\left.\operatorname{Rrs}_{6}\right)$ compares well with the data obtained in other studies $[13,14]$. Several potential determinants were found to be associated with the bronchodilator response in the univariate analysis, but, in accordance with previous studies [12-14, 31], only the baseline value of $\operatorname{Rrs}_{6}$ was significantly associated with $\Delta \operatorname{Rrs}_{6}$ (either expressed relative to the baseline value or as $\mathrm{z}$-score change). This finding that narrower airways at baseline demonstrate the largest bronchodilator response points to bronchomotor tone variability as an important source of the variability in airway resistance in young children. Furthermore, 
baseline AX and current height were independently associated with $\triangle \mathrm{AX}$, whereas the contribution of the height to the regression model was almost negligible when compared with that of the baseline value of AX.

In conclusion, the results of this study demonstrated that the current height, LRTIs after the first year of life, the timing of wheeze and early-onset sensitisation to inhalant allergens were independent determinants of the baseline lung function in 4-year-old children. Furthermore, the baseline lung function was found to be the main determinant of the bronchodilator-induced change in lung function. Preschool children with higher Rrs and AX values at baseline appear to have a larger bronchodilator response.

\section{Acknowledgements}

We thank the families for their participation, and the PIPO project personnel and nurses for the recruitment, follow-up and lung function measurements of the children: C. Daenen, R. Heyndrickx, R. Vroom, D. Stappers and F. Willekens (University of Antwerp, Antwerp, Belgium).

\section{References}

1 Turner SW, Palmer LJ, Rye PJ, et al. The relationship between infant airway function, childhood airway responsiveness, and asthma. Am J Respir Crit Care Med 2004; 169: 921-927.

2 Rasmussen F, Taylor DR, Flannery EM, et al. Risk factors for airway remodeling in asthma manifested by a low postbronchodilator FEV1/vital capacity ratio: a longitudinal population study from childhood to adulthood. Am J Respir Crit Care Med 2002; 165: 1480-1488.

3 Vonk JM, Postma DS, Boezen HM, et al. Childhood factors associated with asthma remission after 30 year follow up. Thorax 2004; 59: 925-929.

4 Bisgaard H, Bønnelykke K. Long-term studies of the natural history of asthma in childhood. J Allergy Clin Immunol 2010; 126: 187-197.

5 Beydon N, Davis SD, Lombardi E, et al. An official American Thoracic Society/European Respiratory Society statement: pulmonary function testing in preschool children. Am J Respir Crit Care Med 2007; 175: 1304-1345.

6 Lau S, Illi S, Sommerfeld C, et al. Multicentre Allergy Study Group. Transient early wheeze is not associated with impaired lung function in 7-yr-old children. Eur Respir J 2003; 21: 834-841.

7 Lercher P, Schmitzberger R. Birth weight, education, environment, and lung function at school age: a community study in an alpine area. Eur Respir J 1997; 10: 2502-2507.

8 Lowe L, Murray CS, Custovic A, et al. Specific airway resistance in 3-year-old children: a prospective cohort study. Lancet 2002; 359: 1904-1908.

9 Moshammer H, Hoek G, Luttmann-Gibson H, et al. Parental smoking and lung function in children: an international study. Am J Respir Crit Care Med 2006; 173: 1255-1263.

10 Lowe LA, Woodcock A, Murray CS, et al. Lung function at age 3 years: effect of pet ownership and exposure to indoor allergens. Arch Pediatr Adolesc Med 2004; 158: 996-1001.

11 Håland G, Lødrup Carlsen KC, Mowinckel P, et al. Lung function at $10 \mathrm{yr}$ is not impaired by early childhood lower respiratory tract infections. Pediatr Allergy Immunol 2009; 20: 254-260.

12 Calogero C, Parri N, Baccini A, et al. Respiratory impedance and bronchodilator response in healthy Italian preschool children. Pediatr Pulmonol 2010; 45: 1086-1094.

13 Malmberg LP, Pelkonen A, Poussa T, et al. Determinants of respiratory system input impedance and bronchodilator response in healthy Finnish preschool children. Clin Physiol Func Imag 2002; 22: 64-71.

14 Thamrin C, Gangell CL, Udomittipong K, et al. Assessment of bronchodilator responsiveness in preschool children using forced oscillations. Thorax 2007; 62: 814-819.

15 Asher MI, Keil U, Anderson HR, et al. International Study of Asthma and Allergies in Childhood (ISAAC): rationale and methods. Eur Respir J 1995; 8: 483-491.

16 Oostveen E, MacLeod D, Lorino $\mathrm{H}$, et al. The forced oscillation technique in clinical practice: methodology, recommendations and future developments. Eur Respir J 2003; 22: 1026-1041.

17 Oostveen E, Dom S, Desager K, et al. Lung function and bronchodilator response in 4-year-old children with different wheezing phenotypes. Eur Respir J 2010; 35: 865-872.

18 Dencker M, Malmberg LP, Valind S, et al. Reference values for respiratory system impedance by using impulse oscillometry in children aged 2-11 years. Clin Physiol Funct Imag 2006; 26: 247-250.

19 Bisgaard H, Pedersen S, Anhøj J, et al. Determinants of lung function and airway hyperresponsiveness in asthmatic children. Respir Med 2007; 101: 1477-1482.

20 Stick SM, Burton PR, Gurrin L, et al. Effects of maternal smoking during pregnancy and a family history of asthma on respiratory function in newborn infants. Lancet 1996; 348: 1060-1064.

21 Martinez FD, Wright AL, Taussig LM, et al. Asthma and wheezing in the first six years of life. New Engl J Med 1995; 332: 133-138.

22 Goldman MD, Carter R, Klein R, et al. Within- and between-day variability of respiratory impedance, using impulse oscillometry in adolescent asthmatics. Pediatr Pulmonol 2002; 34: 312-319.

23 Hall GL, Sly PD, Fukushima T, et al. Respiratory function in healthy young children using forced oscillations. Thorax 2007; 62: 521-526.

24 Illi S, von Mutius E, Lau S, et al. Perennial allergen sensitisation early in life and chronic asthma in children: a birth cohort study. Lancet 2006; 368: 763-770.

25 Jackson DJ, Evans MD, Gangnon RE, et al. Evidence for a causal relationship between allergic sensitization and rhinovirus wheezing in early life. Am J Respir Crit Care Med 2012; 185: 281-285.

26 Guilbert TW, Singh AM, Danov Z, et al. Decreased lung function after preschool wheezing rhinovirus illnesses in children at risk to develop asthma. J Allergy Clin Immunol 2011; 128: 532-538.

27 Kusel MM, de Klerk NH, Kebadze T, et al. Early-life respiratory viral infections, atopic sensitization, and risk of subsequent development of persistent asthma. J Allergy Clin Immunol 2007; 199: 1105-1110. 
28 Sly PD, Boner AL, Björksten B, et al. Early identification of atopy in the prediction of persistent asthma in children. Lancet 2008; 372: 1100-1106.

29 Stein RT, Sherrill D, Morgan WJ, et al. Respiratory syncytial virus in early life and risk of wheeze and allergy by age 13 years. Lancet 1999; 354: 541-545.

30 Hemmelgarn B, Ernst P. Airway function among Inuit primary school children in far northern Quebec. Am J Respir Crit Care Med 1997; 156: 1870-1875.

31 Hellinckx J, De Boeck K, Bande-Knops J, et al. Bronchodilator response in 3-6.5 years old healthy and stable asthmatic children. Eur Respir J 1998; 12: 438-443. 